\title{
Polyester Composites Reinforced with Corona-Treated Fibers from Pine, Eucalyptus and Sugarcane Bagasse
}

\author{
Ricardo Gabriel de Almeida Mesquita ${ }^{1,2}$ - Antônia Amanda da Silva César ${ }^{1}$ • \\ Rafael Farinassi Mendes ${ }^{1}$ - Lourival Marin Mendes ${ }^{1} \cdot$ José Manoel Marconcini $^{3}$. \\ Greg Glenn ${ }^{4}$ Gustavo Henrique Denzin Tonoli ${ }^{1}$
}

Published online: 14 October 2016

(c) Springer Science+Business Media New York 2016

\begin{abstract}
This study aims to evaluate plant fibers that were surface activated with $\mathrm{NaOH}$ and corona discharge before incorporating in ortho unsaturated polyester-based fiber composites. It demonstrates the potential use of lignocellulosic particles, especially eucalyptus that presented the higher values for all the mechanical properties analyzed. The corona discharge treatment increased impact strength and tensile strength of the composites, and decreased water absorption. SEM images showed that the surface activation generally improved the interfacial adhesion between fibers and polyester matrix. Corona treatment may depolymerize the lignocellulosic material and smaller fragments may actually help increase the interaction with the polyester.
\end{abstract}

Keywords Plant fibers - Lignocellulosic residues · Polyester resin · Vegetable fibers · Surface activation

\section{Introduction}

The use of unsaturated polyester for several applications is of interest due to several favorable characteristics such as: (1) low cost; (2) ease of curing at room temperature; (3) ease

Gustavo Henrique Denzin Tonoli

gustavotonoli@yahoo.com.br

1 Department of Forest Science, Universidade Federal de Lavras (UFLA), Cx P. 3037, Lavras, MG 37200-000, Brazil

2 Department of Geosciences and Natural Resource Management, University of Copenahgen (UCHP), Rolighedsvej 23, 1958 Frederiksberg C, Denmark

3 Embrapa Instrumentação, Rua XV de Novembro, 1452, São Carlos, SP CEP 13560-970, Brazil

4 Bioproducts Research Unit, WRRC, ARS-USDA, Albany, CA 94710, USA of molding; (4) good balance of mechanical, electrical, and chemical properties; and (5) a wide experience base in developing technologies and design parameters [1-3].

The increasing interest in plant fiber-based composites is due to the possibility of improving the mechanical properties of products, reducing material costs, or both $[4,5]$. Plant fibers have relative low cost, high mechanical strength, low abrasiveness, broad availability, and low density. They are also renewable, non-toxic and non-pollutant $[6,7]$. Some plant fibers such as wood [8, 9], sisal [10-13], jute [14], kenaf [3], and sugarcane bagasse [15] have potential for use as reinforcing elements in composite materials.

Cellulose-based fibers are intrinsically polar due to the presence of hydroxyl and carboxylic groups in their structure [16]. The major drawback in using these hydrophilic plant fibers in polyester-based composites (that consists of a hydrophobic polymer) is that the interfacial adhesion is poor [3, 17]. Furthermore, the plant fiber component remains susceptible to moisture and, potentially, to fungal and bacteria growth. Thus, when exposed to water, untreated plant fibers have a relatively high wateruptake that makes fibers swell, generating voids and affecting the dimensional stability and strength of the composite $[18,19]$. In these conditions the potential of the plant fibers is underutilized because their strength is not fully utilized for reinforcing the polymeric matrix [20]. To overcome this, in many cases the fiber surface is chemically modified or compatibilizers are used prior to composite fabrication [3, 16, 21-25]. These treatments may decrease the swelling of plant fibers when exposed to water and improve their dimmensional stability.

The chemical or physical treatment of fibers is currently an area of research receiving significant attention. In previous work, the modification of lignocellulosic fibers with alkali $[26,27]$ and silanes [28] successfully enhanced the flexural 
strength and flexural modulus of the composites. However, the problem of water-uptake of the composites was not resolved. Other efforts [29, 30] were successful in improving the mechanical properties and water resistance of composites through treatment with 1,6-diisocyanatohexane and 2-hydroxylethyl acrylate, and with $N$-methylol acrylamide. In spite of the success of these treatments in modifying plant fibers, there is still a need for less polluting chemical reagents that further improve the mechanical properties and water resistance of plant fiber-polyester composites.

Corona discharge is an alternative technology for modifying the surface property of fibers. It is used for the surface activation of synthetic polymers (e.g. polyethylene before printing) and woods (e.g. graft polymerization of vinyl monomer or ethylene imine to wood) [31, 32]. Corona discharge is generally used to improve wettability, adhesion, hydrophilic properties [25, 33] or to graft molecules on polymeric surfaces [34-36]. Compared to chemical routes, polymer (that includes lignocellulosic materials) activation by corona discharge proffers many advantages: high efficiency and economic feasibility [37]; environmental acceptability as an eco-friendly, solvent-free process with the flexibility for application as a continuous process [36]; modificaction of surface properties without affecting bulk properties [38], can be performed under different atmospheres [36], and allows a large range of species to be grafted [35, 39]. The extent of improvement depends on the treatment parameters, such as time and current. Sakata et al. [40] showed that the contact angle of a droplet of urea-formaldehyde resin on a wood surface decreases by increasing the degree of corona treatment. In that case, the improved wettability was reported to lead to higher bond strength.

Success in growing the market for industrial products containing plant fibers will depend on fiber treatments that improve their functionality and performance. The effect of different plant fiber morphologies and of surface activation with alkali and corona discharge on the performance of the polyester-based composites has rarely been reported in the literature. The objective of this study was to evaluate the impact of surface activation of lignocellulosic fibers (pine, eucalyptus, and sugarcane bagasse) with alkali and corona discharge on the performance of plant fiber reinforced polyester-based composites.

\section{Experimental}

\section{Materials}

Three types of lignocellulosic fibers were used: pine (Pinus oocarpa), eucalyptus (Eucalyptus grandis) and sugarcane bagasse (Saccharum officinarum). These fibers were chosen because of their wide availability in Brazil. The eucalyptus and pine trees were obtained from an experimental plantation (Lavras/MG, Brazil) and the sugarcane bagasse was obtained from an ethanol plant located in Southern Minas Gerais, Brazil. The lignocellulosic materials were processed in a hammer mill with a 12 mesh sieve, then sieved through a 20 mesh sieve and collected on a 24 mesh sieve. The material collected on the 24 mesh sieve consisted of elongated, sliver shaped particles that will be called in the present work as fibers. These fiber particles were actually comprised of several individual lignocellulosic fibers (or tracheids in the case of pine).

The polymer matrix used here was composed of ortho unsaturated polyester resin. Methyl-ethyl-ketone peroxide was used as catalyst (both donated by Fibrasil Industria e Comercio Ltda., Brazil).

\section{Characterization of the Lignocellulosic Fibers}

Measurements (length-L, width-W and lumen diameter- $\phi$ ) of the individual fibers and tracheids that form the fiber particles were performed using an Olypus BX41 microscope, with the aid of Wincel Regent PRO software. Each of the morphological features was measured in at least 30 fibers. Anatomical terms describing the fibers were used as recommended by the International Association of Wood Anatomists [41]. Some parameters were calculated for individual fibers such as flexibility coefficient and wall fraction [42-44]. Lumen is the empty cavity in the cell, while the cell diameter includes the lumen plus the cell walls that surround the lumen. The flexibility coefficient (FC) is given by the ratio between the fiber lumen diameter and the fiber cell diameter, expressed in percentage. The wall fraction (WF) is the ratio between cell wall thickness and cell radius, expressed in percentage.

The chemical analyses (lignin, extractives and ash) were conducted according to the Brazilian standards, and holocellulose (cellulose + hemicelluloses) content was determined by weight difference [45].

\section{Chemical and Physical Treatments of the Fibers}

The three types of lignocellulosic fibers were treated with a solution of sodium hydroxide $(\mathrm{NaOH})$ at $\mathrm{pH}=12$ for $2 \mathrm{~h}$. This alkaline treatment was used to promote two effects on the fiber: increase surface roughness resulting in better interfacial adhesion and increase the amount of cellulose uncovered on the fiber surface, thus increasing the number of free hydroxyl $(\mathrm{OH})$ groups exposed as possible reaction sites $[26,46]$. Following the alkaline treatment, the fibers were subjected to a corona discharge (Plasma-Tech, model P-1, Corona Brasil Ldta.) for $5 \mathrm{~min}$, using an applied potential of $12 \mathrm{kV}$, a current of $60 \mathrm{~mA}$ and a frequency of $60 \mathrm{~Hz}$. The discharge was performed in air $\left(25 \pm 3{ }^{\circ} \mathrm{C}\right.$, 
$70 \pm 5 \%$ relative humidity- $\mathrm{RH})$ at an average distance of $2 \mathrm{~cm}$ between the sample and the electric source. The corona treatment excites the free hydroxyl groups and also changes the surface energy, which serves to improve the compatibility between the fiber and the matrix [47].

\section{Production of the Composites}

The composites were prepared by mixing solutions of ortho unsaturated polyester resin with the catalyst and the lignocellulosic fibers. Sugarcane bagasse fibers incorporated into the polyester led to viscosities that were too high for handling compared to the other fiber sources. The maximum sugarcane bagasse fiber concentration that could be incorporated into the composites was $15 \%(\mathrm{w} / \mathrm{w})$. This was due to the lower density and high volume of sugarcane bagasse fibers relative to the other fiber sources. The mixture was poured into steel-framed molds greased with silicone to facilitate de-molding. After curing, the specimens were de-molded and conditioned $\left(22 \pm 2{ }^{\circ} \mathrm{C}, 65 \pm 5 \% \mathrm{RH}\right)$ until a constant weight was achieved. The different steps in preparing the composites with treated and untreated fibers are shown schematically in Fig. 1.

\section{Characterization of the Composites}

X-ray radiography was performed with a Faxitron MX-20 $\mathrm{X}$-ray instrument to evaluate the formation of bubbles and eventual failures in the composite structure.

An EMIC DL 3000 universal testing machine was used in the tensile and bending tests. Tensile strength was determined following the ASTM D638-01 [48] standard using around eight replicates, a test speed of $5 \mathrm{~mm} / \mathrm{min}$, and load cell of 3,000 Kgf. Bending tests were performed using a three point bending apparatus as recommended by ASTM D790-00 [49] standard, using at least five replicates, a test speed of $2 \mathrm{~mm} / \mathrm{min}$, and a load cell of $50 \mathrm{Kgf}$.

The Izod impact tests were performed using a Tinius Olsen with a hammer of $2.82 \mathrm{~J}$. The tests were carried out in accordance with the ASTM D256-10 [50] standard using ten replicates.

Water absorption was performed with the immersion of the composites in water for different periods, in agreement with the ASTM D570-98 [51] standard.

Boxplot charts were used for descriptive statistical analysis of the mechanical properties and water absorption of the composites. The asterisk is the average value; the horizontal line in middle of each boxplot shows the median value; the margins of the box show the 25 and $75 \%$ quartiles; lines outside the box correspond to the largest data points (5 and $95 \%$ quartiles) that are not evaluated as outliers. The outliers (when available) are plotted by the plus signs.

The morphology of the fracture surface of the composites after tensile tests was observed in a scanning electron microscope (SEM) Zeiss/DSM 940A, operated at $15 \mathrm{kV}$. Fracture surfaces were gold coated before SEM visualization.

\section{Results and Discussion}

\section{Fiber Characterization}

Table 1 shows the anatomical properties of the individualized fibers from the lignocellulosic material used in the
Fig. 1 Illustrative scheme of the treatments and fiberreinforced composites

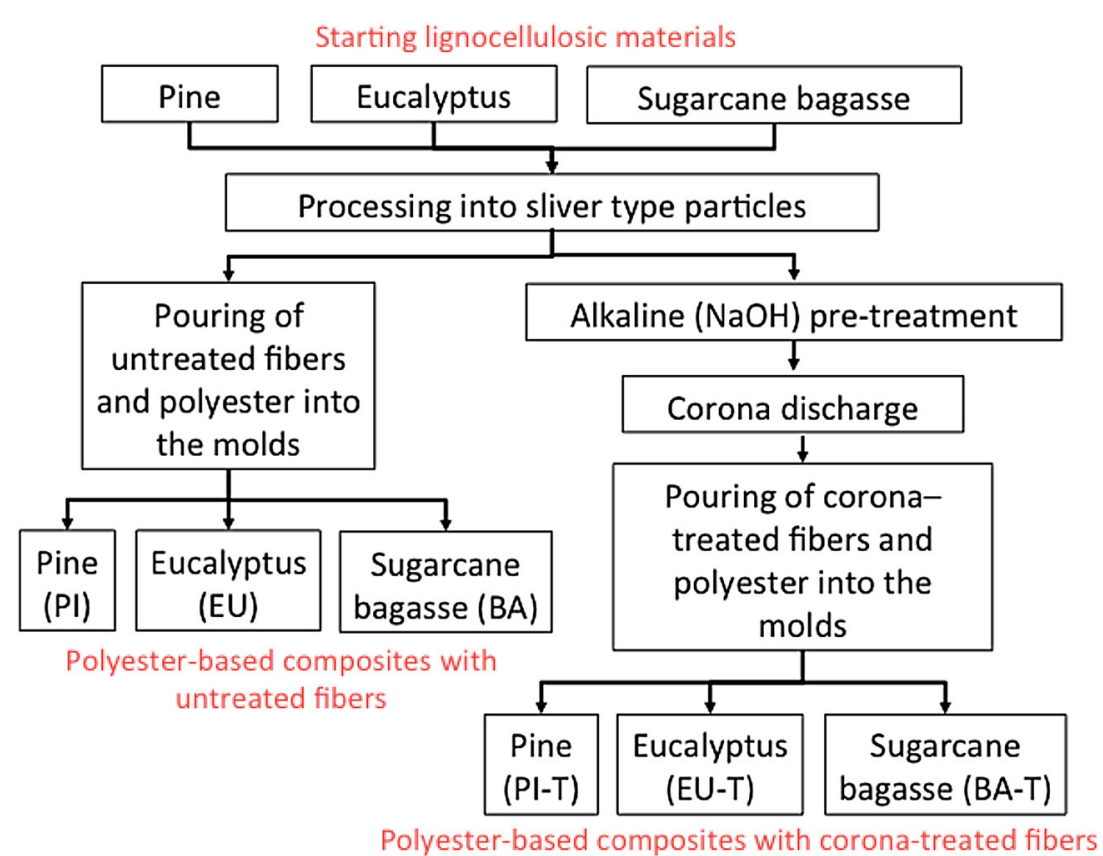


composites. The values of the fiber cell length (L) and width $(\mathrm{W})$ are in agreement with the literature wherein eucalyptus had the smallest fiber length, sugarcane bagasse fibers were intermediate, and the pine fibers had the greatest length. Long and narrow fibers have a higher aspect ratio compared to short and wide fibers. Fibers with a high aspect ratio are preferable because they confer higher mechanical properties for the composites [52].

The wall fraction (WF) is related to the rigidity of the fiber cell and values above $60 \%$ are normally related to stiffer fibers [52]. Pine was the material that showed the lowest WF values and the higher flexibility coefficient (FC), similar to values observed for Pinus taeda [53]. The WF of eucalyptus fibers was very close to $60 \%$, similar to that for Eucalyptus grandis [54].

Table 2 presents the chemical composition of the lignocellulosic materials. Eucalyptus and pine fibers have higher holocellulose content. Sugarcane bagasse had the highest ash content among the particle fibers tested. High levels of ash, lignin, and soluble extractives are believed to decrease the mechanical strength of fiber composites by interfering with interfacial adhesion and increasing the fiber pull-out [55]. The higher mineral content of sugarcane bagasse can be observed in the X-ray images (Fig. 2). Silica $\left(\mathrm{SiO}_{2}\right)$, which is a well-known component of the sugarcane bagasse, was visualized as dark spots in the radiographs due to its high density in relation to the other fiber components.

\section{Mechanical Properties of the Composites}

Figures 3, 4 and 5 are boxplot charts used for descriptive statistical analysis of the physico-mechanical properties of the composites. They indicate a high degree of variability in the data when the differences between major and minor responses (outside line of the box) are high. Moderate
Table 1 Morphological characteristics of the individualized lignocellulosic fibers

Table 2 Chemical composition of the lignocellulosic materials

\begin{tabular}{lccllll}
\hline Fibers & $\mathrm{L}(\mu \mathrm{m})$ & $\phi(\mu \mathrm{m})$ & $\mathrm{T}(\mu \mathrm{m})$ & $\mathrm{W}(\mu \mathrm{m})$ & $\mathrm{FC}(\%)$ & $\mathrm{WF}(\%)$ \\
\hline Pine & 3154.3 & 44.2 & 6.9 & 51.4 & 86.0 & 26.7 \\
Eucalyptus & 988.8 & 8.4 & 5.2 & 18.5 & 45.4 & 55.9 \\
Sugarcane bagasse & 2133.5 & 13.9 & 6.5 & 27.4 & 50.8 & 47.3 \\
\hline
\end{tabular}

L, fiber cell length; $\phi$, lumen diameter; T, cell wall thickness; W, fiber cell width; FC, flexibility coefficient; WF, wall fraction

\begin{tabular}{lllll}
\hline Material & Extractives (\%) & Lignin $(\%)$ & Ash $(\%)$ & Holocellulose $(\%)$ \\
\hline Pine & 2.7 & 29.3 & 0.2 & 67.8 \\
Eucalyptus & 3.2 & 26.5 & 0.4 & 69.9 \\
Sugarcane bagasse & 2.7 & 28.6 & 7.5 & 61.2 \\
\hline
\end{tabular}

Fig. 2 X-ray radiography images of the composites reinforced with sugarcane bagasse, pine and eucalyptus. This image permits the easy identification of high-density phases since photon scattering increases with the increase in atomic number. Dark areas in the image (due to high atomic number) pertain to cross or longitudinal sections of the mineral species (e.g. $\mathrm{SiO}_{2}$ content)
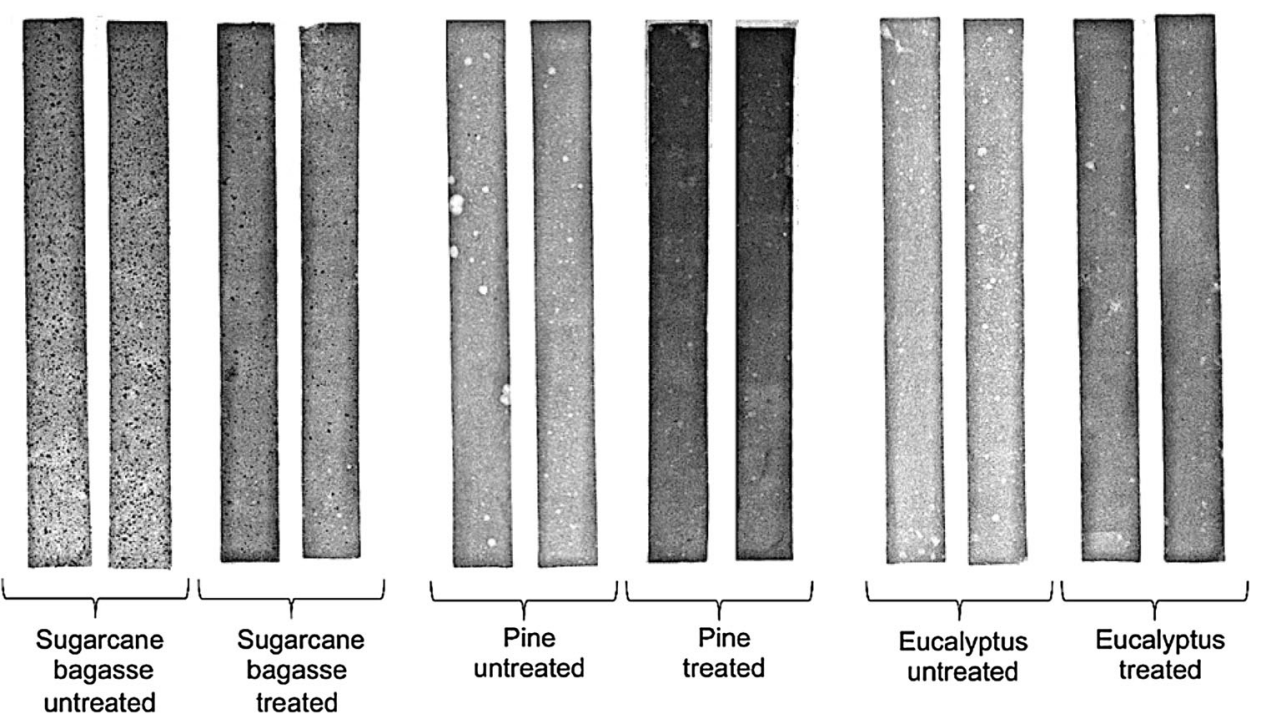


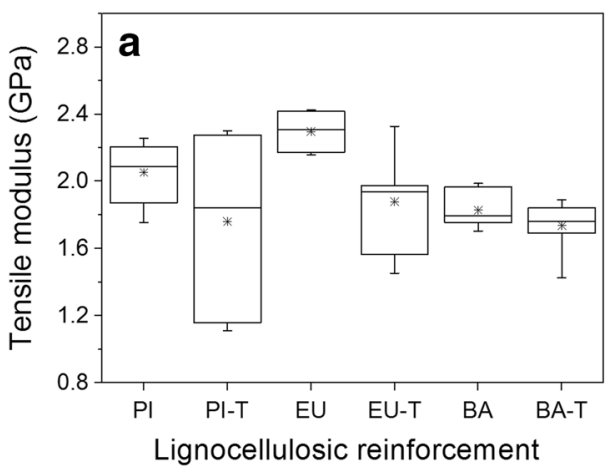

Fig. 3 Boxplot of a modulus of elasticity under tensile and $\mathbf{b}$ tensile strength of the composites reinforced with the different lignocellulosic fibers. BA, sugarcane bagasse fibers; BA-T, corona-treated sugarcane bagasse fibers; EU, eucalyptus fibers; EU-T, corona-treated eucalyptus fibers; PI, pine fibers; PI-T, corona-treated pine fibers. The

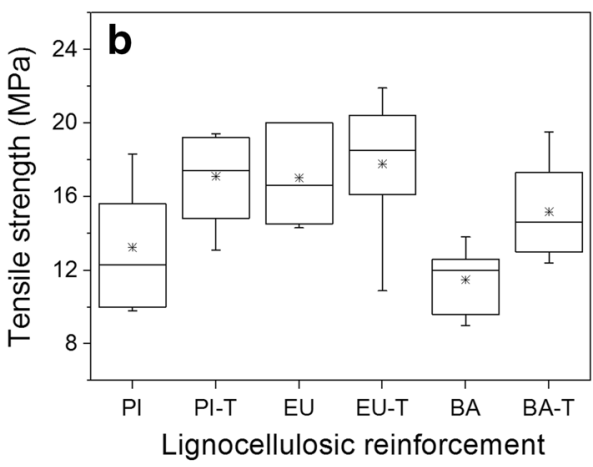

asterisks are the average values, the horizontal line in the middle of each boxplot shows median values; margins of the box give 25 and $75 \%$ quartiles; lines outside box correspond to the largest data points that are not evaluated as outliers

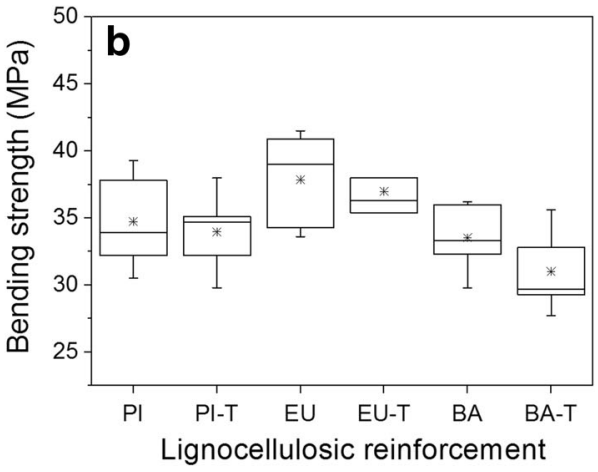

pine fibers. The asterisks are the average values, the horizontal line in the middle of each boxplot shows median value; margins of the box give 25 and $75 \%$ quartiles; lines outside box correspond to the largest data points that are not evaluated as outliers

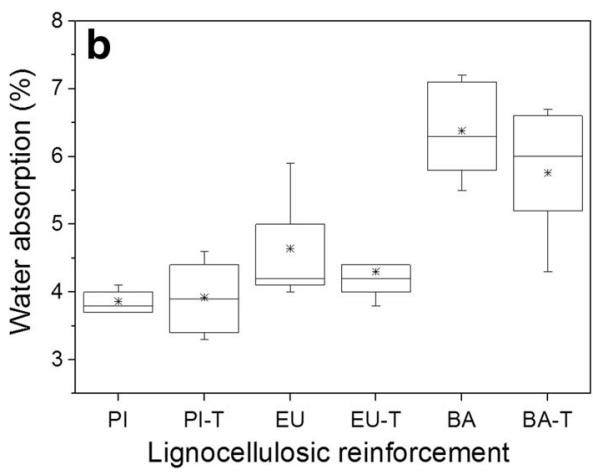

average values, the horizontal line in the middle of each boxplot shows median value; margins of the box give 25 and $75 \%$ quartiles; lines outside box correspond to the largest data points that are not evaluated as outliers 
differences generally indicate a uniform spread whilst data distributions are reasonably symmetrical and the interquartile values across the range are similar. There were no data points considered as outliers in the entire set.

Composites reinforced with sugarcane bagasse had the lowest strength when compared to composites reinforced with pine and eucalyptus. This may be related to the lower mechanical strength of sugarcane bagasse fibers [56] due to their high content of parenchyma cells and the effect of the milling process (during the ethanol production). The higher median values of modulus of elasticity in the tensile and bending tests of composites reinforced with eucalyptus fibers are probably related to the WF of the fibers. Another important factor that contributed to the higher performance of the eucalyptus-reinforced composites may be related to their higher cellulose content. Eucalyptus fibers contain high amount of holocellulose, and it is well know that cellulose is largely responsible for the mechanical strength of the fibers. The lowest values of modulus of elasticity in tensile (Fig. 3a) and bending tests (Fig. 4a) for pine and bagasse-reinforced composites may be related to the lower values of wall fraction and higher flexibility coefficient of these fibers (Table 1). Pine composites showed higher variability of data for tensile modulus, while values were less variable for tensile strength (Fig. 3b).

Even using lower amount of reinforcement, the average bending strength for pine and eucalyptus-reinforced composites in the present work was higher than that found elsewhere, evaluating composites of high density polyethylene with $20 \%$ pine and eucalyptus sawdust [57]. However, the tensile strength values obtained in the present work were lower than that former work. The proportion of sawdust influenced the tensile strength [58] and this may explain the lower values found in this study when $15 \%$ (by mass) of fibers was used. The modulus of elasticity in the bending test for bagasse-reinforced composites was similar to that found in literature, however the values of modulus of elasticity under tensile were higher than values published elsewhere for polyester composites reinforced with $15 \%$ of sugarcane bagasse fibers [53].

The treatment of the fibers with $\mathrm{NaOH}$ and corona discharges decreased average values of modulus of elasticity under bending (up to $26 \%$ decrease for eucalyptus), bending strength (up to $7 \%$ decrease for sugarcane bagasse) and modulus of elasticity under tensile (up to $18 \%$ decrease for eucalyptus) for all kinds of fiber reinforcement. The corona discharge treatment seemed to act negatively to these properties and this was especially true for bending modulus, which showed the most significant reduction in the average values after treatments. For bending modulus, data variability was low, but variability of values for bending strength was higher for untreated fibers (Fig. 4). The bending strength of the composites depended on the interaction between the fiber and matrix and on the properties of the reinforcing element. Therefore, the chemical treatment and the corona discharge seems to have degraded the cellulose chains, as also reported by Uehara and Sakata [31] that showed evidence of chemical changes and chain scission of cellulose by corona treatment. A decrease in the fiber tenacity was observed with increasing of corona energy level and time of exposure [16, 36, 59]. Sakata et al. [40] reported on the oxidation of hydrophilic constituents of the surface of different types of wood through corona treatments. However, it is expected that chemical changes induced by corona treatment were restricted to the substrate surface and did not affect the bulk properties of corona-treated wood [40]. Some authors also observed a decrease in the bending strength values when jute fibers were exposed to 5 and $15 \mathrm{~min}$ of plasma discharge in polyester-based composites [14]. Heating the fibers by using high exposure times or high-energy conditions, could degrade the fibers by depolymerisation (because they are low molecular weight species) or decreasing of crystallinity as previously suggested [16].

Otherwise, the smaller fragments from depolymerization of the lignocellulosic material may help increase interaction with the polyester chains. This could account for the higher tensile strength values (Fig. 3b) for composites with treated fibers were higher (up to $32 \%$ increase for sugarcane bagasse) than composites reinforced with untreated fibers. Furthermore, the removal of excess cellulose, lignin and alkali soluble impurities from the surface layer of fibers by $\mathrm{NaOH}$ treatment enhanced surface roughness, made the fiber soft, adhering easily to the polyester, and improved the mechanical interlocking at the fiber-matrix interface [60]. The use of alkali treated fiber as reinforcement results in significant increases in tensile strength, flexural strength and impact strength of composites [61]. This increase is probably due to the removal of the excess cellulose, lignin and wax content present over the hydrophilic fiber surface by means of alkali degradation [62]. Additionally, corona discharge treatment is thought to activate the molecules at the surface, producing many activated sites along the polymeric chains of the fiber. The size and number of micro-pits increased with treatment time [36]. Thus, the roughness of the corona-treated fiber tends to increase as already reported by Zheng et al. [63] on polymeric materials. According to Gassan and Gutowski [16], corona-treated fibers exhibited significantly higher polar components of the free surface energy with increasing treatment energy output; which is mainly due to increasing the content of carboxyl and hydroxyl groups.

The impact strength values of the composites with corona-treated pine and bagasse fibers were higher (20 and $10 \%$, respectively) than the composites with untreated fibers. The rough surface found around the alkali treated 
fiber contributed to better stress transference between the matrix and fiber, which in turn resulted in better absorption of impact energy through uniform fiber breakage [62]. The eucalyptus-reinforced composites showed high data variability for impact strength (Fig. 5a). It was observed that the treatment of the fibers (in a low extent to eucalyptus treated fibers) seems to increase the data variability for the composite properties. Therefore, other factors require consideration and may contribute to the spread in the collected data, such as difficulties with corona treatment on
Fig. 6 Hypothetical mechanism for surface activation of the cellulose fibers. Free radicals formed by bond cleavage between: (1) with $\mathrm{C} 1$ and ring oxygen (Mechanism A); or (2) with $\mathrm{C} 1$ and glycosidic oxygen bond (Mechanism B). Adapted from Ward et al. [69]

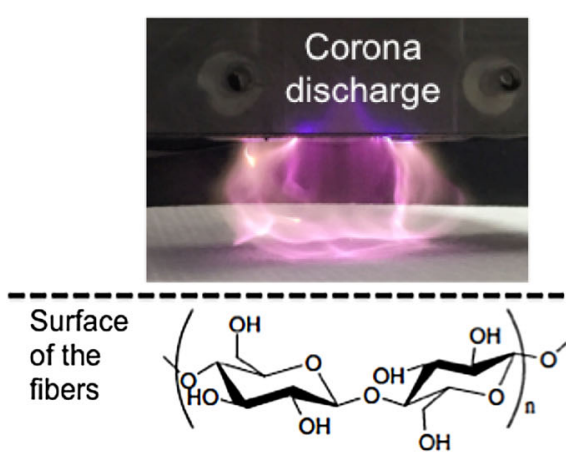

Cellulose $\beta-1,4$

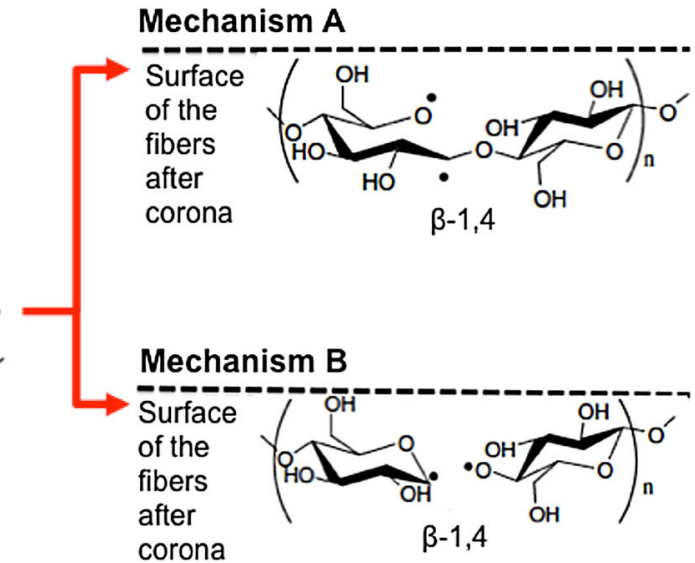

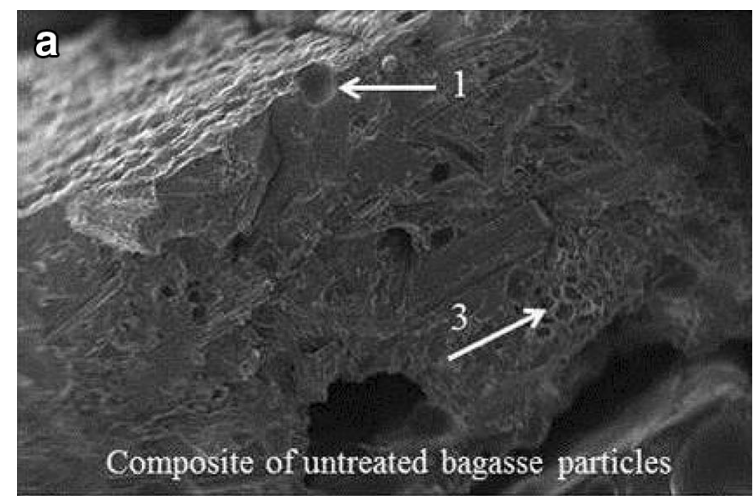

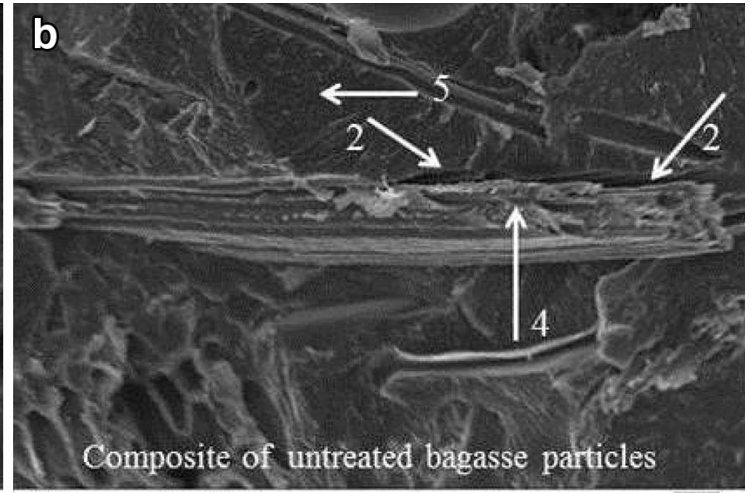

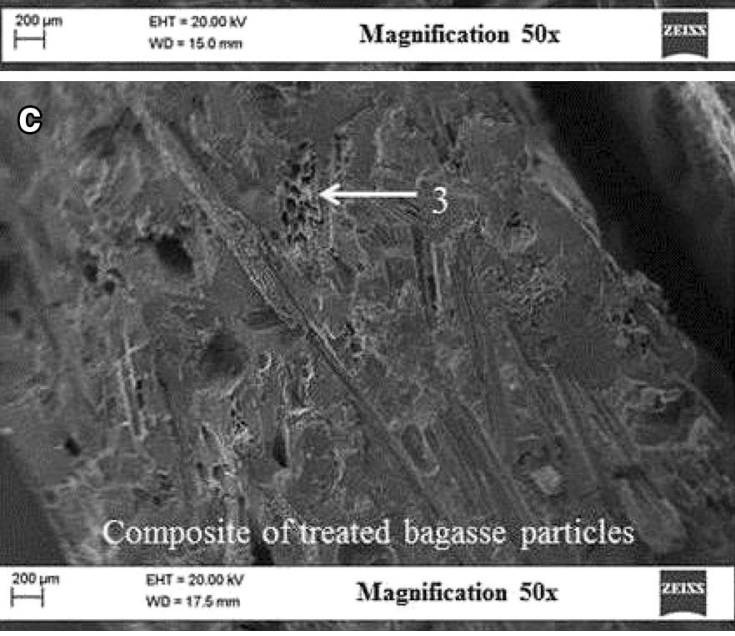

Fig. 7 SEM micrographs of the fracture surface of the composites reinforced with sugarcane bagasse fibers: $\mathbf{a} \times 50$ magnification (BA); b $\times 500$ magnification $(\mathrm{BA}) ; \mathbf{c} \times 50$ magnification $(\mathrm{BA}-\mathrm{T}) ; \mathbf{d} \times 500$ magnification (BA-T). Arrows indicate: (1) presence of air bubbles;

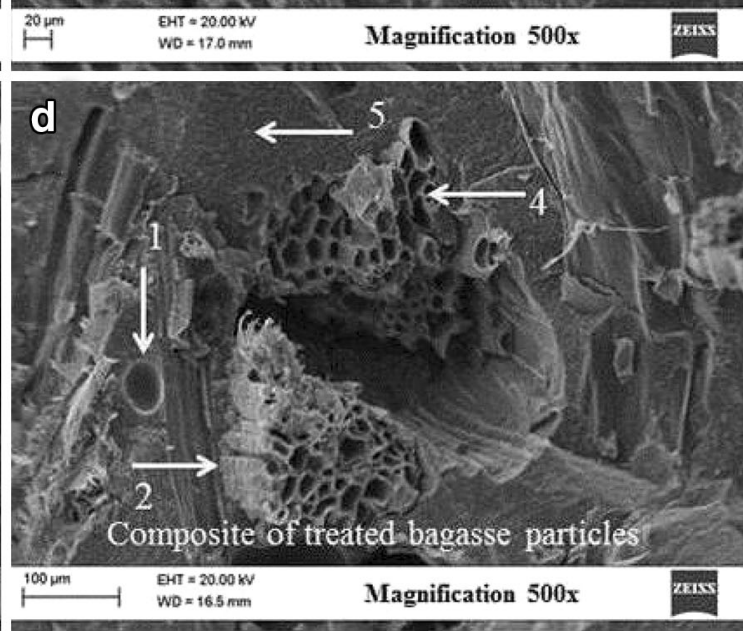

(2) fiber-matrix interface region; (3) surface left by the pull-out of sugarcane bagasse fiber; (4) detail of the sugarcane bagasse fiber; and (5) polyester matrix 
three dimensional objects [64], or with the 'underneath' side not directly exposed to the bombardment by ionised species present in the discharge zone [16].

It is also expected that surface roughness increased with the treatment time as a consequence of the increase of surface density of oxygenated species such as carboxylic $(\mathrm{COOH})$ and hydroxyl $(\mathrm{OH})$ groups, increasing interaction at the fiber-matrix interface. Therefore, a balance between the increase in surface roughness and the decrease of the fiber strength is necessary to successfully improve the composite strength [16].

\section{Water Absorption of the Composites}

Water absorption (WA) of the polyester resin is almost null, since it has expressive hydrophobic properties. The hydrophilic lignocellulosic fibers were likely responsible for much of the water absorption of the composite. Agricultural residues (such as sugarcane bagasse) typically have lower density and higher percentage of hemicellulose compared to wood. This composition could result in a greater amount of binding sites for water resulting in higher water uptake [65]. Water uptake can break the secondary bonds between matrix and fibers, decreasing the interaction between them. Also, the water absorption by the fibers can lead to dimension instability. Those effects can decrease the mechanical properties of the composites, as observed by Zadorecki and Flodin [66] testing polyester composites reinforced with cellulose after water immersion and compared to dry conditions.

Composites reinforced with sugarcane bagasse had the highest WA values (Fig. 5b). The WA values for all formulations were lower than those previously reported [56], whose WA values were around $10 \%$ after $72 \mathrm{~h}$ of water immersion. Some authors evaluated different wood fibers in composites based on low-density polyethylene, and also observed lower water absorption for pine-reinforced composites [67]. The authors attributed this behavior to the improved interaction of the pine fibers (probably due to the lower polar contribution of the lignin and extractives in these fibers) with the polymer matrix and the lower percentage of cellulose in this species. A higher variability was observed for tensile properties in sugarcane bagasse (with and without treatment) composites.
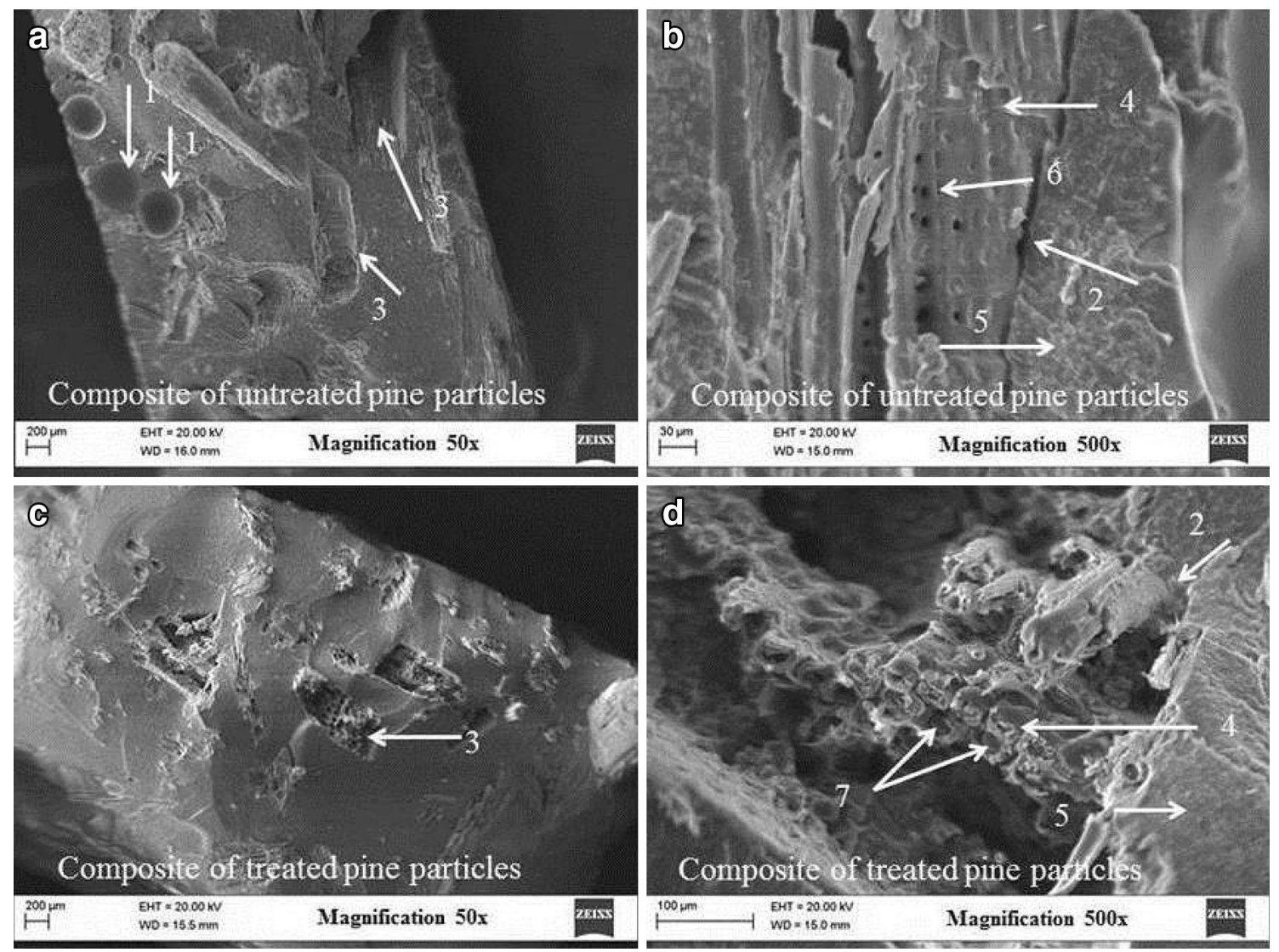

Fig. 8 SEM micrographs of the fracture surface of the composites reinforced with pine fibers: $\mathbf{a} \times 50$ magnification $(\mathrm{PI}) ; \mathbf{b} \times 500$ magnification $(\mathrm{PI}) ; \mathbf{c} \times 50$ magnification $(\mathrm{PI}-\mathrm{T}) ; \mathbf{d} \times 500$ magnification (PI-T). Arrows indicate: (1) formation of air bubbles; (2) fiber-matrix

interface region; (3) surface left by the pull-out of the pine fiber; (4) pine tracheid; (5) polyester matrix: (6) pits in the pine tracheids, and (7) polyester matrix present in the lumen of the pine tracheid 
The WA values of the composites reinforced with treated fibers are similar to the untreated pine fibers. A reduction of 7 and $9 \%$ in the average WA values was observed for composites with treated sugarcane bagasse and eucalyptus respectively, in relation to untreated samples. According to Benhadi et al. [36], after the corona treatment, oxygen O1s content increases while that of carbon $\mathrm{C} 1 \mathrm{~s}$ decreases. Nevertheless, it can be assumed the formation of oxygen-containing functional groups such as esters, carboxyl and carbonyl, by reaction of carbon present at the cellulose surface and oxygen atmosphere as reported by Belgacem et al. [68]. According to Ward et al. [69], cellulose radicals generated by plasma treatments can result from of one of the following mechanisms shown in Fig. 6: (1) bond breakage between $\mathrm{C} 1$ and ring oxygen (Mechanism A); (2) bond breakage between $\mathrm{C} 1$ and glycosidic bond oxygen (Mechanism $\mathrm{B}$ ). The $\mathrm{O}-\mathrm{C}-\mathrm{O}$ groups might partially originate from pectic substances, as also found in literature [70]. Mihailovic et al. [37] demonstrated that the amount of $\mathrm{C}-\mathrm{OH}, \mathrm{C}-\mathrm{O}-\mathrm{C}$ and $\mathrm{O}-\mathrm{C}-\mathrm{O}$ groups significantly decreased after corona, and consequently, the surface roughness increases. According to those authors, corona treatment led to creation of a uniform nano-sized grain-like fiber topography [37]. Park et al. [71] also reported the increase of surface roughness of the fibers with the increase of the power of corona discharge. Hence, different new functionalities such as $\mathrm{C}-\mathrm{O}, \mathrm{O}-\mathrm{C}-\mathrm{O}, \mathrm{O}=\mathrm{C}-\mathrm{O}, \mathrm{C}=\mathrm{O}$ and $\mathrm{O}-\mathrm{CO}-\mathrm{O}$ can be formed [72], depending on the nature of the gas and plasma operating conditions. Uehara and Sakata [31] reported the increase of aldehyde groups content with increase in the corona discharge time. Actually, according to those authors, the aldehyde groups are often unstable, and then they are easily converted to carboxyl groups by autoxidation.

\section{Microstructure of the Composites}

SEM micrographs depict a weak interaction between fibers and polymer matrix for all the untreated fibers tested (Figs. 7, 8, 9). The low degree of interfacial adhesion was probably due to the differences in the affinity of the hydrophobic matrix and the hydrophilic lignocellulosic fibers. The gap at the fiber-matrix interface was observed on the surface of the untreated fibers in the composites (Figs. 7b, 8b, 9b), showing poor interfacial adhesion between untreated fibers and the polyester matrix. The corona-treated fibers presented smaller gaps over the untreated fibers (Figs. 7d, 8d, 9d), which may have
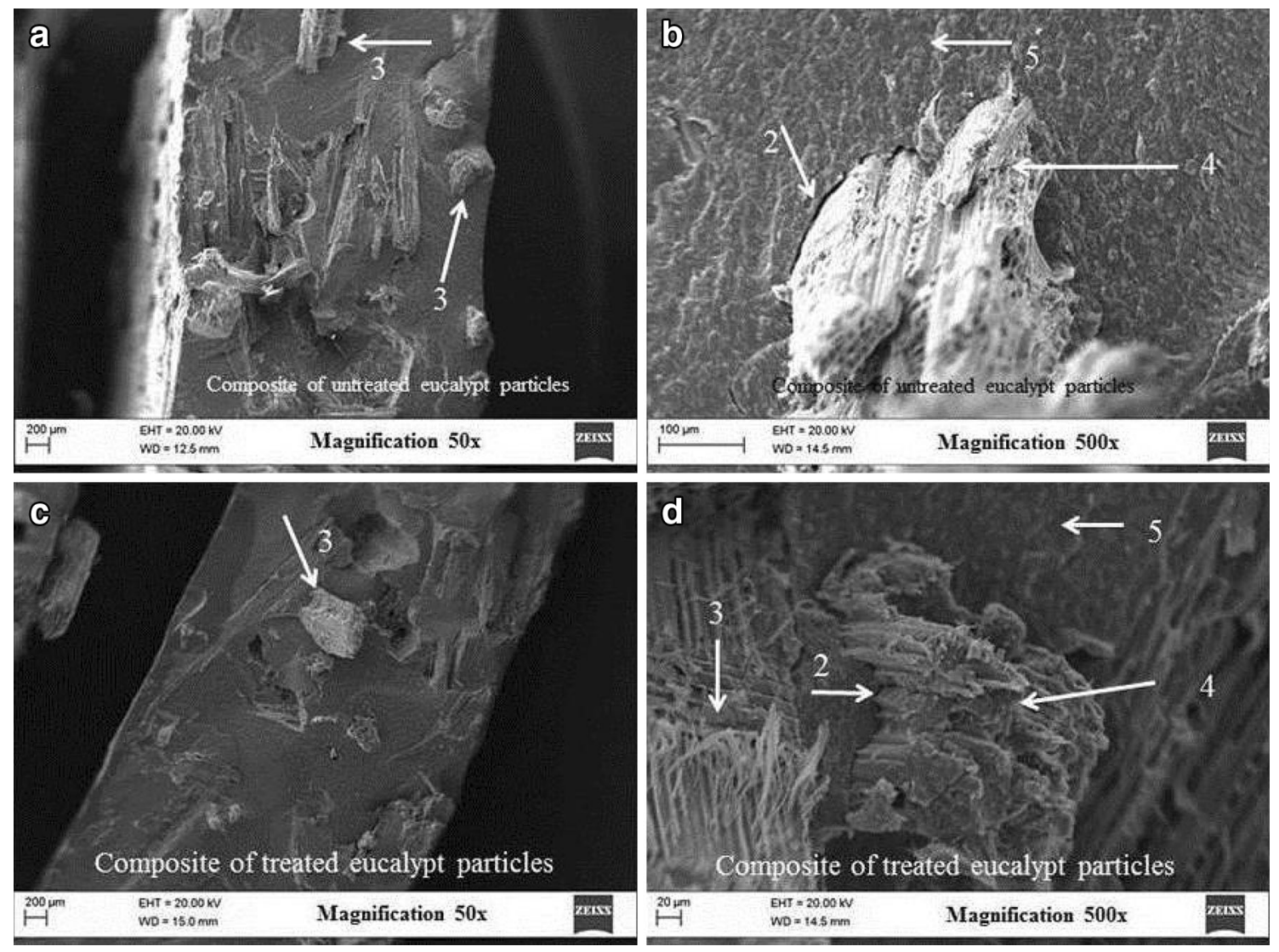

Fig. 9 SEM micrographs of the fracture surface of the composites reinforced with eucalyptus fibers: $\mathbf{a} \times 50$ magnification $(\mathrm{EU}) ; \mathbf{b} \times 500$ magnification (EU); c $\times 50$ magnification $($ EU-T); $\mathbf{d} \times 500$

magnification (EU-T). Arrows indicate: (2) fiber-matrix interface region; (3) eucalyptus pulled-out fibers; (4) particle of eucalyptus fibers; and (5) polyester matrix 
contributed to the increase in the average tensile (Fig. 3b) and impact strength (Fig. 5a) of the composites with corona-treated pine and sugarcane bagasse fibers. The improvement in mechanical properties may have occurred due to the enhanced effective stress transfer from the polyester matrix to the fibers.

As discussed in the previous sections, the decrease of voids at the fiber-matrix interface can be a consequence of the creation of small fragments at the fiber surface of the corona-treated fibers [73]. Figure 8d (arrow 7) shows the polyester matrix present in the lumen of corona-treated pine tracheids, which is probably a consequence of increasing wettability with applying corona discharge. It seems easier for the polyester to slide between the tightlypacked cellulose polymer structure in corona-treated fibers. This is an unexpected finding for untreated fibers considering the hydrophobic character of the polyester resin and its relatively high molecular weight [66].

The SEM micrographs corroborate with the observations in the X-ray radiographs (Fig. 2) that show the presence of bubbles (air voids) in pine-reinforced composites, which have negatively affected the mechanical strength. The composites with corona-treated fibers presented fewer bubbles, which also had higher tensile strength and lower WA. The enhanced adhesion minimized the gap between fibers and matrix, thus facilitating the wetting and penetration of the resin in the fibers.

\section{Conclusions}

Among the composites analyzed, the eucalyptus-reinforced composites had the superior mechanical performance (bending, tensile and impact strength). The improved performance is probably due to the higher strength of the eucalyptus fibers. Pine-reinforced composites showed the lower water absorption, probably because of the hydrophobic character of the extractives and lower polar contribution of the lignin in this type of fiber. Activation of the fiber surfaces with $\mathrm{NaOH}$ and corona discharges increased impact strength (in the pine and bagasse-reinforced composites), decreased water absorption (in eucalyptus and bagasse-reinforced composites) and increased tensile strength (in all reinforced composites). SEM micrographs showed that these treatments generally improved wettability and the interfacial adhesion between fibers and polyester matrix, despite probably causing some damage to the fibers if treatment time is to long. Corona discharge constitutes an interesting and promising route to activate plant fiber surfaces and to functionalize polymer materials. Corona discharge offers many advantages for surface activation including being a solvent-free technique that can be applied as a continuous process. The present work contributes with information about corona discharge under atmospheric $\left(25 \pm 3{ }^{\circ} \mathrm{C}\right.$ and $70 \pm 5 \%$ RH $)$ conditions for the activation of lignocellulosic fiber surfaces. Corona discharge could potentially find more widespread use in the development of composites for multi-purpose applications. Further work is ongoing to study the influence of corona discharges on the pull-out stress for fibers in composite materials.

Acknowledgments Authors thank to Universidade Federal de Lavras (UFLA) for supporting the experimental work, and also thank the financial support granted by Coordenação de Aperfeiçoamento de Pessoal de Nível Superior (CAPES), Conselho Nacional de Desenvolvimento Científico e Tecnológico $(\mathrm{CNPq})$ and Fundação de Amparo à Pesquisa do Estado de Minas Gerais (FAPEMIG). Thanks also to Fibrasil Indústria e Comércio Ltda. (Lavras/MG, Brazil), PGCTM (UFLA), LME (UFLA) and Brazilian Research Network in Lignocellulosic Composites and Nanocomposites - RELIGAR.

\section{References}

1. Yang H, Lee LJ (2001) J Appl Polym Sci 79:1230

2. Alsina OLS, Carvalho LH, Ramos FFG, Almeida JRM (2005) Polym Test 24:81

3. Ren X, Li K (2013) Investigation of vegetable-oil-based coupling agents for kenaf-fiber-reinforced unsaturated polyester composites. J Appl Polym Sci 128(2):1101-1109

4. Callister WD Jr (2002) Materials science and engineering: an introduction, 5th edn. LTC, Rio de Janeiro

5. Raghu K, Kahanam PN, Naidu SV (2010) Chemical resistence studies of silk/sisal fiber-reinforced unsaturade polyester-based hybrid composites. J Reinf Plast Compos 29(3):343-345

6. Macvicar R, Matuana LM, Balatinecz JJ (1999) Aging mechanism in cellulose fiber reinforced cement composites. Cem Concr Compos 21:89-96

7. Soykeabkaew N, Sian C, Gea S, Nishino T, Peijs T (2009) Allcellulose nanocomposites by surface selective dissolution of bacterial cellulose. Cellulose 16:435-444

8. Ayrilmis N, Jarusombuti S, Fuengvivat V, Bauchongkol P (2011) Effect of thermal-treatment of wood fibres on properties of flatpressed wood plastic composites. Polym Degrad Stab 96:818-822

9. Hosseinaei O, Wang S, Taylor AM, Kim JW (2012) Effect of hemicelluloses extraction on water absorption and mold susceptibility of wood-plastic composites. Int Biodeterior Biodegrad 7:29-35

10. Carvalho LH, Cavalcanti WS (2006) Properties of polyester/ hibrid sisal-glass fabrics. Polim Sci Technol 16(1):33-37

11. Joseph K, Medeiros ES, Carvalho LH (1999) Polyester matrix composites reinforced by short fibers sisal. Sci Technol, Polim, pp 136-141

12. Vieira CAB, Mondadore NML, Freire E, Amico SC, Zattera AJ (2009) Interference wash performance fibers on the mechanical properties of sizing hybrid composite glass/sisal. J Iber Am Polym 10(4):222-234

13. Teixeira RS, Tonoli GHD, Santos SF, Savastano H Jr, Protásio TP, Toro EF, Maldonado J, Lahr FAR, Delvasto S (2014) Different ageing conditions on cimentitious roofing tiles reinforced with alternative vegetable and synthetic fibres. Mater Struct 47(3):433-446

14. Sinha E, Panigrahi S (2009) Effect of plasma treatment on structure, wettability of jute fiber and flexural strength of its composite. J Compos Mater 43(17):1791-1802 
15. Ramesh M, Palanikumar K, Hemachandr RK (2013) Mechanical property evaluation of sisal-jute-glass fiber reinforced polyester composites. Compos B 48:1-9

16. Gassan J, Gutowski VS (2000) Effects of corona discharge and UV treatment on the properties of jute-fibre epoxy composites. Compos Sci Technol 60:2857-2863

17. Cruz VCA, Nóbrega MMS, Silva WP, Carvalho LH, Lima AGB (2011) An experimental study of water absorption in polyester composites reinforced with macambira natural fiber. Materialwissenschaft und Werkstofftechnik 42(11):979-984

18. Akil HM, Cheng LW, Ishak ZM, Bakar AA, Rahman MA (2009) Compos Sci Technol 69:1942

19. Law TT, Ishak ZM (2011) J Appl Polym Sci 120:563

20. Mehta G, Mohanty AK, Misra M, Drzal LTJ (2004) Mater Sci 39:2961

21. Benítez AN, Monzón MD, Angulo I, Ortega Z, Hernandez PM, Marrero MM (2013) Treatment of banana fiber for use in the reinforcement of polymeric matrices. Measurement 46:1065-1073

22. Garkhail SK, Heijenrath RWH, Peijs T (2000) Mechanical properties of natural-fibre-mat-reinforced thermoplastics based on flax fibres and polypropylene. Appl Compos Mater 5:351-372

23. Pasquini D, Belgacem MN, Gandini A, Curvelo AAS (2006) Surface esterification of celulose fibers: characterization by DRIFT and contect angle measurements. J Colloid Interface Sci 295:79-83

24. Sawpan MA, Pickering KL, Fernyhough A (2011) Effect of fibre treatments on interfacial shear strength of hemp fibre reinforced polylactide and unsaturated polyester composites. Compos A 42:1189-1196

25. Belgacem MN, Bataille P, Sapieha S (1994) Effect of corona modification on the mechanical properties of polypropylene/cellulose composites. J Appl Polym Sci 53:379-385

26. Li X, Tabil 1G, Panagrahi S (2007) Chemical treatments of natural fiber for use in natural fiber-reinforced composites: a review. J Polym Environ 15:25-33

27. Aziz SH, Ansell MP (2004) J Compos Sci Technol 64:1219

28. Cho D, Lee HS, Han SO (2009) Compos Interface 16:711

29. Ren X, Qiu R, Li K (2012) J Appl Polym Sci 125:2846

30. Ren X, Qiu R, Fifield LS, Simmons KL, Li K (2012) Effects of surface treatments on mechanical properties and water resistance of kenaf fiber-reinforced unsaturated polyester composites. J Adhes Sci Technol 26(18-19):2277-2289

31. Uehara T, Sakata I (1990) Effect of corona discharge treatment on cellulose prepared from beech wood. J Appl Polym Sci 41:1695-1706

32. Dong S, Sapieha S, Schreiber HP (1993) Mechanical properties of corona-modified cellulose/polyethylene. Polym Eng Sci 33(6):343-346

33. Ooi SK, Vanderhoek N, Morrison R, Bauer A (2004) Atmospheric plasma treatment (APT), understanding the basics. In: Appita annual conference, pp 407-412

34. Seto F, Muraoka Y, Akagi T, Kishida A, Akashi M (1999) Surface grafting of poly(vinylamine) onto poly(ethylene) film by corona discharge-induced grafting. J Appl Polym Sci 72:1583-1587

35. Bataille P, Dufourd M, Sapieha S (1994) Copolymerization of styrene onto cellulose activated by corona. Polym Int 34:387-391

36. Benhadi S, Ragoubi M, Joly J-P, Molina S, George B, Brosse N (2011) Corona discharge treatment route for the grafting of modified $\beta$-cyclodextrin molecules onto cellulose. J Incl Phenom Macrocycl Chem 70:143-152

37. Mihailović D, Saponjić Z, Radoicić M, Lazović S, Baily CJ, Jovancić P, Nedeljković J, Radetic M (2011) Functionalization of cotton fabrics with corona/air RF plasma and colloidal $\mathrm{TiO}_{2}$ nanoparticles. Cellulose 18:811-825
38. Lei J, Shi M, Zhang J (2000) Surface graft copolymerisation of hydrogen silicone fluid onto fabrics through corona discharge and water repellency of grafted fabrics. Eur Polym J 36:1277-1281

39. Bataille P, Dufourd M, Sapieha S (1991) Graft polymerization of styrene onto cellulose by corona discharge. Polym Prepr 32:559-560

40. Sakata I, Morita M, Tsuruta N, Morita K (1993) J Appl Polym Sci 49:1251

41. International Association of Wood Anatomists (1989) Iawa list of microscopic features for hardwood identification. Bulletin IAWA, Leiden

42. Fonseca AS, Mori FA, Tonoli GHD, Jr Savastano, Ferrari DL, Miranda IPA (2013) Properties of an Amazonian vegetable fiber as a potential reinforcing material. Ind Crops Prod 47:43-50

43. Paula JE, Alvez JLH (1989) Anatomical study of native woods suitable for energy and paper production. Braz Res Agric 24(12):1461-1471

44. Paula JE (1993) Woods from the caatinga, suitable for energy production. Braz Res Agric 28(2):153-165

45. ABTCP (1974) Technical standards. ABCP, São Paulo

46. Valadez-Gonzales A, Cervantes-UC JM, Olayo R, HerreraFranco PJ (1999) Effect of fiber surface treatment on the fibermatrix bond strength of natural fiber reinforced composites. Compos B Eng 30(3):309-320

47. Bledzki AK, Gassan J (1999) Composites reinforced with cellulose based fibres. Prog Polym Sci 24:221-274

48. ASTM Standard D-638 (2003) Standart test method for tensile properties of plastics. ASTM International, West Conshohocken

49. ASTM Standard D-790 (2000) Standart test methods for bending properties of unreinforced and reinforced plastics and electrical insulaling materials. ASTM International, West Conshohocken

50. ASTM Standard D-256 (2010) Standard test methods for determining the Izod pendulum impact resistance of plastics. ASTM International, West Conshohocken

51. ASTM Standard D-570 (1998) Standard test method for water absorption on plastics. ASTM International, West Conshohocken

52. Guimarães M Jr, Novack KM, Botaro VR (2010) Anatomical characterization of fiber bamboo (Bambusa vulgaris) for their use in polymer composites. J Iber Am Polym 11(7):442-456

53. Nisgoski S (2005) Near infrared spectroscopy in the study of characterization of wood and paper Pinus taeda L. Ph.D. Thesis, Federal University of Parana

54. Paula JE (1995) Anatomy and dendrometry of Mimosa artemisiana and Eucalyptus grandis. Braz Res Agric 30(6):745-757

55. Guimarães M Jr, Novack KM, Botaro VR, Protásio TP (2012) Characterization of Bamboo Pulp chemically modified in order to improve the interfacial interactions in their applications in composites. J Iber Am Polym 13(3):89-102

56. Sanchez EMS, Cavani CS, Leal CV, Sanchez CG (2010) Unsaturated polyester resin composite with sugar cane bagasse: influence of treatment on the fibers properties. Polimeros 20(3): 194-200

57. Hillig E, Iwakiri S, Andrade MZ, Zattera AJ (2008) Characterization of composites made from high density polythylene (HDPE) and furniture industry sawdust. Tree J 32(2):299-310

58. Sathishkumar TP, Navaneeltakrishnan P, Shankar S (2012) Tensile and flexural properties as snake grass natural fiber reinforced isophthallic polyster composites. Compos Sci Technol 72:1183-1190

59. Gutowski WVS, Wu DY, Li S (1993) J Adhes 43:139

60. Gassan J, Bledzki AK (1999) J Appl Polym Sci 71:623

61. Rout J, Nayak S, Misra M, Mohanty AK (2001) J Appl Polym Sci 79:1169

62. Kalyana S, Sundaram S, Jayabal, Nijandhan K (2015) Influence of fiber pretreatment on the mechanical properties of dharbai fiber 
reinforced polyester composites. Cellul Chem Technol 49(1):61-64

63. Zheng Z, Tang X, Shi M, Zhou G (2003) A study of the influence of controlled corona treatment on UHMWPE fibres in reinforced vinylester composites. Polym Int 52:1833-1838

64. Walzak MJ, Flynn S, Foersch R, Hill JM, Karbashewski E, Lin A, Strobel M (1995) J Adhes Sci Technol 9(9):1229

65. Li X, Cai Z, Winandy JE, Basta AH (2011) Effect of oxalic acid and steam pretreatment on the primary properties of UF-bonded rice straw particleboards. Ind Crops Prod 33:665-669

66. Zadorecki P, Flodin P (1986) Properties of cellulose-polyester composites. Polym Compos 7(3):170-175

67. Shebani AN, Van Reenem AJ (2009) The effect of wood species on the mechanical and thermal properties of wood-LLDPE composites. J Compos Mater 43(11):1305-1318

68. Belgacem MN, Czeremuszkin G, Sapieha S, Gandini A (1995) Surface characterization of cellulose fibres by XPS and inverse gas chromatography. Cellulose 11:145-157
69. Ward TL, Jung HZ, Hinojosa O, Benerito RR (1979) Characterization and use of radio frequency plasma-activated natural polymers. J Appl Polym Sci 23:1987-2003

70. Topalovic T, Nierstrasz VA, Bautista L, Jocic D, Navarro A, Warmoeskerken MMCG (2007) XPS and contact angle of cotton surface oxidation by catalytic bleaching. Colloid Surf A 296:76-85

71. Park M, Kim HY, Jin FL, Lee SY, Choi HS, Park SJ (2014) Combined effect of corona discharge and enzymatic treatment on the mechanical and surface properties of wool. J Ind Eng Chem 20:179-183

72. Tourrette O, De Geyterb N, Jocic D, Morent R, Warmoeskerken MMCG, Leys C (2009) Incorporation of poly( $N$-isopropylacrylamide)/chitosan microgel onto plasma functionalized cotton fibre surface. Colloid Surf A 352:126-135

73. Uner B (2009) The effect of support media on corona treated paper sorption properties. Sci Res Essay 4(10):1024-1030 